Number 8

\title{
KADAR GLUKOSA DARAH PUASA PADA IBU HAMIL TRIMESTER II DAN III DI PUSAT KESEHATAN MASYARAKAT I DENPASAR SELATAN
}

\author{
I G.A. Arista Wedanthi ${ }^{1}$, I G.A. Sri Dhyana Putri ${ }^{2}$, Luh Ade Wilan Krisna ${ }^{3}$
}

\begin{abstract}
Background Gestational diabetes mellitus (GDM) was a condition of glucose intolerance that occur during pregnancy detected by examining blood glucose levels.

Objective This study aims to measure fasting blood glucose levels at the second and third trimesters pregnant women in Puskesmas I Denpasar Selatan-based on certain characteristics.
\end{abstract}

Methods The type of this study is descriptive and using simple random sampling technique. Samples in this study amounted to 33 women. Blood glucose levels measured by venous blood samples with hexokinase method.

Result The study results obtained 28 women (84,85\%) in the not risk of GDM category and five women $(15,15 \%)$ in the risk of GDM category. High blood glucose levels obtained four women $(12,12 \%)$ in the category $>25$ years and one women $(3,03 \%)$ in the category $<25$, on the characteristics of the gestational age obtain two women $(6,06 \%)$ in the second trimester and three women $(9,09 \%)$ in the third trimester, on the characteristics of DM in the family obtained one women $(3,03 \%)$ with a history of DM.

Conclusion The conclusion of this research obtained fasting blood glucose level in trimester II and III pregnant women at Puskesmas I Denpasar Selatan ranged between $66-120 \mathrm{mg} / \mathrm{dL}$.

Keywords: blood glucose, pregnant women, gestational diabetes

\section{PENDAHULUAN}

Kehamilan merupakan kondisi yang berlangsung selama 280 hari saat wanita mengandung janin hasil konsepsi dalam tubuhnya hingga kelahiran ${ }^{1}$. Kehamilan akan berpengaruh terhadap perubahan hormon diantaranya Human Chorionic Somatomammotropin, kortisol, progesteron, dan prolaktin. Komplikasi yang mungkin terjadi selama kehamilan akibat adanya perubahan hormon tersebut yaitu diabetes melitus gestasional ${ }^{2}$.
Diabetes Melitus Gestasional merupakan suatu keadaan intoleransi glukosa yang terjadi atau pertama kali ditemukan pada saat kehamilan ${ }^{3}$.

Diabetes melitus gestasional terjadi sekitar 2-5\% dari semua kehamilan. Wanita hamil dengan diabetes gestasional hampir tidak pernah memberikan keluhan, sehingga perlu dilakukan skrining. Pemeriksaan skrining diawali dengan parameter pemeriksaan glukosa sewaktu 
atau puasa kemudian dapat diikuti dengan Tes Toleransi Glukosa Oral. Hasil yang menunjukkan nilai normal maka harus dilakukan pemeriksaan ulang pada minggu kehamilan antara 24-28 minggu ${ }^{3}$ karena biasanya peningkatan kadar glukosa darah yang signifikan terdeteksi pada mingguminggu tersebut ${ }^{4}$, Hormon chorionic somatomammotropin akan disekresi dengan konsentrasi yang terus meningkat selama kehamilan, termasuk trimester III kehamilan ${ }^{2}$.

Berdasarkan Data Kesehatan Ibu dan Anak (KIA) di Puskesmas I Denpasar Selatan tercatat jumlah data mengenai tafsiran kelahiran pada tahun 2017 mulai bulan Maret hingga Agustus tercatat sebesar 61 kelahiran. Dari 61 kelahiran tersebut, terdapat $29 \mathrm{ibu}$ hamil yang memiliki usia diatas 25 tahun. Usia saat kehamilan > 25 tahun merupakan salah satu faktor risiko terjadinya diabetes gestasional $^{2}$

\section{Penatalaksanaan DMG bertujuan} menurunkan angka kesakitan atau kematian ibu dan perinatal. Hal tersebut dapat tercapai dengan mempertahankan kadar glukosa normal selama kehamilan hingga kelahiran ${ }^{5}$. Pemeriksaan glukosa darah bukan merupakan pemeriksaan rutin kehamilan, namun tingginya kadar glukosa selama kehamilan bahkan pada ibu dengan usia produktif merupakan faktor risiko terjadinya diabetes gestasional. Selain itu, wanita dengan diabetes gestasional hampir tidak pernah memberikan keluhan padahal diabetes gestasional dapat menyebabkan komplikasi yang tidak hanya mengganggu kesehatan ibu namun juga kesehatan bayinya. Keadaan tersebut membuat peneliti tertarik untuk melakukan penelitian mengenai Gambaran Kadar Glukosa Darah Puasa pada Ibu Hamil Trimester II dan III di Pusat Kesehatan Masyarakat I Denpasar Selatan.

\section{METODE}

Jenis penelitian yang digunakan yaitu penelitian deskriptif untuk menggambarkan tentang kadar glukosa darah puasa pada ibu hamil trimester II dan III di Puskesmas I Denpasar Selatan berdasarkan usia ibu, usia kehamilan, riwayat melahirkan bayi makrosomia, riwayat diabetes melitus dan riwayat diabetes gestasional. Pemeriksaan sampel dilakukan di Laboratorium Patologi Klinik RSUP Sanglah Denpasar. Penelitian ini dilaksanakan Januari hingga Juni 2017. Subjek pada penelitian ini adalah ibu hamil trimester II dan III yang tercatat dalam kantong tafsiran kelahiran bulan Maret hingga Agustus di Puskesmas I Denpasar Selatan yang memenuhi kriteria penelitian. Sampel diambil dengan menggunakan teknik probability sampling metode simple random sampling. Metode 
I G.A. Arista Wedanthi, dkk., Kadar Glukosa Darah Puasa Pada Ibu Hamil Trimester II dan III di Pusat Kesehatan Masyarakat I Denpasar Selatan

yang digunakan dalam pemeriksaan Berdasarkan hasil pemeriksaan glukosa darah puasa yaitu metode heksokinase. Pada penelitian ini kadar glukosa darah puasa yang menjadi faktor risiko kejadian diabetes melitus gestasional yaitu dengan kadar $\geq 95$ $\mathrm{mg} / \mathrm{dL}$.

\section{HASIL DAN PEMBAHASAN}

laboratorium, diperoleh rata-rata kadar glukosa darah puasa pada subjek penelitian sebesar $83,7 \mathrm{mg} / \mathrm{dL}$ dengan kadar glukosa darah terendah $66 \mathrm{mg} / \mathrm{dL}$ dan tertinggi 120 mg/dL. Hasil Pemeriksaan Kadar Glukosa Darah Puasa pada Ibu Hamil dapat dilihat pada Tabel 1.

\section{Hasil}

Tabel 1

Hasil Pemeriksaan Kadar Glukosa Darah Puasa pada Ibu Hamil

\begin{tabular}{cccc}
\hline $\begin{array}{c}\text { Kadar gula darah } \\
(\mathrm{mg} / \mathrm{dL})\end{array}$ & Jumlah & $\begin{array}{c}\text { Prosentase } \\
(\%)\end{array}$ & Kategori \\
\hline$<95$ & 28 & 84,85 & tidak berisiko mengalami DMG \\
$\geq 95$ & 5 & 15,15 & berisiko mengalami DMG \\
\hline Total & 33 & 100 & \\
\hline
\end{tabular}

Hasil pemeriksaan kadar glukosa sebanyak 20 orang $(60,61 \%)$. darah puasa pada subjek penelitian Selengkapnya hasil pemeriksaan kadar berdasarkan karakteristik usia ibu hamil diperoleh jumlah data terbanyak pada kategori $<95 \mathrm{mg} / \mathrm{dL}$ dengan usia berisiko glukosa darah puasa pada subjek penelitian berdasarkan karakteristik usia dapat dilihat pada Tabel 2.

mengalami DMG (> 25 tahun) yaitu

Tabel 2

Hasil Pemeriksaan Kadar Glukosa Darah Puasa pada Subjek Penelitian Berdasarkan Karakteristik Usia

\begin{tabular}{cccccccc}
\hline \multirow{2}{*}{ Usia ibu hamil } & \multicolumn{3}{c}{ Kadar glukosa darah puasa } & \multirow{2}{*}{ Total } \\
\cline { 2 - 6 } & \multicolumn{2}{c}{$<95$} & \multicolumn{2}{c}{$\geq 95$} & \\
\cline { 2 - 6 } & $\Sigma$ & $\%$ & $\Sigma$ & $\%$ & $\Sigma$ & $\%$ \\
\hline Usia tidak berisiko DMG $(\leq 25)$ & 8 & 24,24 & 1 & 3,03 & 9 & 27,27
\end{tabular}


I G.A. Arista Wedanthi, dkk., Kadar Glukosa Darah Puasa Pada Ibu Hamil Trimester II dan III di Pusat Kesehatan Masyarakat I Denpasar Selatan

\begin{tabular}{ccccccc} 
Usia berisiko DMG (> 25) & 20 & 60,61 & 4 & 12,12 & 24 & 72,73 \\
\hline Total & 28 & 84,84 & 5 & 15,15 & 33 & 100 \\
\hline
\end{tabular}

Hasil pemeriksaan glukosa darah puasa pada subjek penelitian berdasarkan karakteristik usia kehamilan diperoleh jumlah data terbanyak pada kategori $<95 \mathrm{mg} / \mathrm{dL}$ dengan usia kehamilan pada trimester III yaitu sebanyak 15 orang $(45,45 \%)$. Selengkapnya pemeriksaan kadar glukosa darah puasa pada subjek penelitian berdasarkan karakteristik usia kehamilan dapat dilihat pada Tabel 3.

Tabel 3

Hasil Pemeriksaan Kadar Glukosa Darah Puasa pada Subjek Penelitian Berdasarkan Karakteristik Usia Kehamilan

\begin{tabular}{ccccccc}
\hline \multirow{2}{*}{$\begin{array}{c}\text { Usia } \\
\text { kehamilan }\end{array}$} & \multicolumn{3}{c}{ Kadar glukosa darah puasa } & \multicolumn{3}{c}{ Total } \\
\cline { 2 - 6 } & \multicolumn{2}{c}{$<95$} & \multicolumn{2}{c}{$\geq 95$} & & \\
\cline { 2 - 6 } & $\Sigma$ & $\%$ & $\Sigma$ & $\%$ & & $\%$ \\
\hline Trimester II & 13 & 39,39 & 2 & 6,06 & 15 & 45,45 \\
Trimester III & 15 & 45,46 & 3 & 9,09 & 18 & 54,55 \\
\hline Total & 28 & 84,85 & 5 & 15,15 & 33 & 100 \\
\hline
\end{tabular}

Hasil pemeriksaan kadar glukosa darah puasa pada subjek penelitian berdasarkan karakteristik riwayat melahirkan bayi makrosomia diperoleh jumlah data terbanyak pada kategori $<95$ $\mathrm{mg} / \mathrm{dL}$ dengan tidak memiliki riwayat melahirkan bayi makrosomia pada

Tabel 4

Hasil Pemeriksaan Kadar Glukosa Darah Puasa pada Subjek Penelitian Berdasarkan Karakteristik Riwayat Melahirkan Bayi Makrosomia

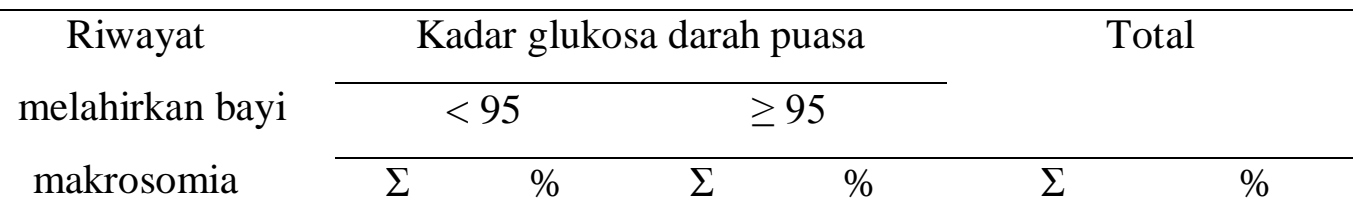


I G.A. Arista Wedanthi, dkk., Kadar Glukosa Darah Puasa Pada Ibu Hamil Trimester II dan III di Pusat Kesehatan Masyarakat I Denpasar Selatan

\begin{tabular}{ccccccc}
\hline Ada & 0 & 0 & 0 & 0 & 0 & 0 \\
Tidak ada & 28 & 84,85 & 5 & 15,15 & 33 & 100 \\
\hline Total & 28 & 84,85 & 5 & 15,15 & 33 & 100 \\
\hline
\end{tabular}

Hasil pemeriksaan kadar glukosa darah puasa pada subjek penelitian berdasarkan karakteristik riwayat diabetes melitus dalam keluarga diperoleh jumlah data terbanyak pada kategori $<95 \mathrm{mg} / \mathrm{dL}$ dengan tidak memiliki riwayat diabetes melitus dalam keluarga yaitu sebanyak 27 orang (81,82\%). Selengkapnya hasil pemeriksaan kadar glukosa darah puasa pada subjek penelitian berdasarkan karakteristik riwayat diabetes melitus dalam keluarga dapat dilihat pada Tabel 5.

Tabel 5

Hasil Pemeriksaan Kadar Glukosa Darah Puasa pada Subjek Penelitian Berdasarkan Karakteristik Riwayat Diabetes Melitus dalam Keluarga

\begin{tabular}{cccccccc}
\hline \multirow{2}{*}{$\begin{array}{c}\text { Riwayat diabetes } \\
\text { melitus dalam keluarga }\end{array}$} & \multicolumn{3}{c}{ Kadar glukosa darah puasa } & \multicolumn{2}{c}{ Total } \\
\cline { 2 - 6 } & \multicolumn{2}{c}{$<95$} & \multicolumn{2}{c}{$\geq 95$} & & \\
\cline { 2 - 6 } & $\Sigma$ & $\%$ & $\Sigma$ & $\%$ & $\Sigma$ & $\%$ \\
\hline Ada & 1 & 3,03 & 1 & 3,03 & 2 & 6,06 \\
Tidak ada & 27 & 81,82 & 4 & 12,12 & 31 & 93,94 \\
\hline Total & 28 & 84,85 & 5 & 15,15 & 33 & 100 \\
\hline
\end{tabular}

Hasil pemeriksaan kadar glukosa darah puasa pada subjek penelitian berdasarkan karakteristik riwayat diabetes gestasional diperoleh jumlah data terbanyak pada kategori < $95 \mathrm{mg} / \mathrm{dL}$ dengan tidak memiliki riwayat diabetes gestasional pada kehamilan sebelumnya yaitu sebanyak 28 orang $(84,85 \%)$. Selengkapnya hasil pemeriksaan kadar glukosa darah puasa pada subjek penelitian berdasarkan karakteristik riwayat diabetes 
gestasional dapat dilihat pada Tabel 6.

Tabel 6

Hasil Pemeriksaan Kadar Glukosa Darah Puasa pada Subjek Penelitian Berdasarkan Karakteristik Riwayat Diabetes Gestasional

\begin{tabular}{ccccccc}
\hline Riwayat & \multicolumn{3}{c}{ Kadar glukosa darah puasa } & \multicolumn{3}{c}{ Total } \\
\cline { 2 - 6 } diabetes & \multicolumn{3}{c}{$<95$} & \multicolumn{2}{c}{$\geq 95$} & \\
gestasional & $\Sigma$ & $\%$ & $\Sigma$ & $\%$ & $\Sigma$ & $\%$ \\
\hline Ada & 0 & 0 & 0 & 0 & 0 & 0 \\
Tidak ada & 28 & 84,85 & 5 & 15,15 & 33 & 100 \\
\hline Total & 28 & 84,85 & 5 & 15,15 & 33 & 100 \\
\hline
\end{tabular}

\section{Pembahasan}

Hasil pemeriksaan terhadap 33 subjek penelitian diperoleh pada kategori tidak berisiko mengalami DMG yaitu sebanyak 28 orang $(84,85 \%)$ dan kategori berisiko mengalami DMG sebanyak lima orang $(15,15 \%)$. Kadar glukosa darah normal disebabkan karena metabolisme karbohidrat dan fungsi organ yang baik. Jumlah glukosa akan dikendalikan oleh insulin yang dihasilkan oleh pankreas ${ }^{6}$.

Usia produktif untuk hamil yaitu 2030 tahun. Usia kehamilan $\leq 25$ tahun merupakan usia kehamilan yang tidak berisiko mengalami DMG. Hasil penelitian ini ditemukan subjek penelitian dengan usia berisiko DMG (> 25 tahun) memiliki kadar glukosa darah puasa pada kategori berisiko DMG ( $\geq 95 \mathrm{mg} / \mathrm{dL})$. Salah satu faktor risiko terjadinya diabetes gestasional yaitu usia > $25 \operatorname{tahun}^{2}$ dan didukung oleh penelitian Terence, dkk yang menyatakan bahwa risiko diabetes gestasional meningkat secara progresif pada usia diatas 25 tahun $^{7}$. Walaupun pada penelitian ini ditemukan juga subjek penelitian dengan usia $>25$ tahun dengan kadar glukosa darah $<95 \mathrm{mg} / \mathrm{dL}$, hal ini dikarenakan faktor risiko tersebut dapat dihilangkan dengan mengatur pola makan

Peningkatan kadar glukosa darah yang signifikan terjadi pada saat memasuki trimester kedua kehamilan, yakni antara minggu ke 24-28 (Sari, 2014). Hasil penelitian ini ditemukan dua subjek penelitian trimester II dan tiga subjek penelitian trimester III yang memiliki kadar glukosa darah puasa $\geq 95 \mathrm{mg} / \mathrm{dL}$. 
Hal tersebut karena Hormon chorionic somatomammotropin yang muncul pertama kali pada trimester II kehamilan dan akan diproduksi terus meningkat selama trimester III kehamilan ${ }^{2}$.

Berdasarkan data hasil wawancara pada penelitian ini ditemukan dua subjek penelitian $(6,06 \%)$ yang memiliki riwayat diabetes melitus dalam keluarganya satu diataranya memiliki kadar glukosa darah tinggi dan satu lainnya memiliki kadar normal. Kedua subjek penelitian memiliki ayah yang mengidap penyakit diabetes melitus. Orang yang memiliki riwayat keluarga menderita diabetes melitus mempunyai risiko menularkan ke anaknya sebesar 42 kali dibandingkan dengan orang yang tidak memiliki riwayat $^{8}$. Meskipun seseorang mempunyai riwayat diabetes melitus dikeluarganya tidak selalu menentukan orang tersebut menderita diabetes melitus karena terdapat penelitian yang menyatakan tidak terdapat hubungan riwayat diabetes melitus pada keluarga dengan kejadian diabetes melitus gestasional $^{9}$.

Berdasarkan data wawancara pada penelitian ini diperoleh seluruh subjek penelitian tidak memiliki riwayat dalam kehamilan sebelumnya dan enam orang $(18,18 \%)$ diantaranya merupakan kehamilan pertama.

\section{SIMPULAN DAN SARAN}

\section{Simpulan}

Hasil pemeriksaan kadar glukosa darah puasa pada ibu hamil trimester II dan III di Puskesmas I Denpasar Selatan berkisar antara $66-120 \mathrm{mg} / \mathrm{dL}$ dengan rata-rata $83,7 \mathrm{mg} / \mathrm{dL}$, diperoleh 28 orang $(84,85 \%)$ dengan kadar glukosa darah puasa < $95 \mathrm{mg} / \mathrm{dL}$ dan lima orang $(15,15 \%)$ dengan kadar glukosa darah puasa

$\geq 95 \mathrm{mg} / \mathrm{dL}$. Peningkatan kadar glukosa darah puasa terjadi pada ibu dengan usia berisiko DMG (12,12\%), pada trimester III kehamilan (9,09\%), pada karakteristik riwayat diabetes melitus dalam keluarga didapatkan satu subjek penelitan $(3,03 \%)$ dengan riwayat DM.

\section{Saran}

Kepada ibu hamil sebaiknya menjaga pola hidup sehat dan melakukan skrining glukosa pada saat awal kehamilan dan melakukan pemeriksaan kembali pada trimester II kehamilan, sehingga kadar glukosa darah akan tetap seimbang dan mencegah timbulnya penyakit diabetes melitus gestasional.

\section{DAFTAR PUSTAKA}

1. Winson, N dan S. Mcdonald. 2008. Kamus Kebidanan Bergambar. Alih Bahasa: Dwi Widiarti. Jakarta : EGC medical publisher.

2. Dewi, R.K. 2014. Diabetes Bukan Untuk Ditakuti Tetap Sehat dengan Pengaturan Pola Makan bagi Penderita Diabetes Tipe 2. Jakarta: FM media. 
3. Adam, J.MF. 2006. Buku ajar Ilmu Penyakit Dalam jilid III edisi IV. Editor: Sudoyo, A.W., B. Setiyohadi, I. Alwi, M. Simadibrata K, dan S. Setiati. Jakarta: Departemen Ilmu Penyakit Dalam Fakultas Kedokteran Universitas Indonesia.

4. Sari, K. 2014. Pengaruh Diabetes pada Kehamilan. Editor : Hafid. Online. https://books.google.co.id/books?id=gBS1CA AAQBAJ\&pg=PA36\&lpg=PA36\&dq=pelacak an+terhadap+diabetes+gestasional+biasanya\& source $=$ bl\&ots $=$ vawR7YV6Mp\&sig $=S 1 b 4 K X$ HB9bTyIXIfF4BfZkmzGY\&hl=id\&sa=X\&ve $\mathrm{d}=0$ ahUKEwj3vPPmsZHSAhWGrY8KHS3aA

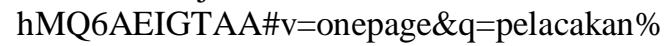
20terhadap\%20diabetes\%20gestasional\%20bia sanya \&f=false. Diakses tanggal 15 Februari 2017.

5. Dalimarta, S., F.Adrian. 2012. Makanan dan Herbal untuk Penderita Diabetes Melitus. Jakarta: Penebar Swadaya.

6. Rafanani, B. 2012. Panduan Pola Makan Sehat \& Cerdas Bagi Penderita Diabetes. Yogyakarta: Araska.

7. Terence, L., H. 1. Fong, C. Ben, L. Wing, dan Cheong. 2014. Maternal Age and Prevalence of Gestational Diabetes Mellitus. [Online]. http://care.diabetesjournals.org/content/29/4/94 8.full.pdf+html. Diakses tanggal 6 Juli 2017

8. Wicaksono, R.P. 2011. Faktor-Faktor yang Berhubungan Dengan Kejadian Diabetes Melitus $\quad$ Tipe $2 . \quad$ Online. http://eprints.undip.ac.id/37104/1

/Radio_P.W.pdf. Diakses tanggal 28 Juni 2017

9. Pamolango, M.A., B. Wantouw, dan J. Sambeka. 2013. Hubungan Riwayat Diabetes Melitus pada Keluarga dengan Kejadian Diabetes Melitus Gestasional pada Ibu Hamil Di Pkm Bahu Kec. Malalayang Kota Manado. Online.https://ejournal.unsrat.ac.id/index.php/j kp/article/view/2203. Diakses 28 Juni 2017. 